\title{
Characterization of one sheep border disease virus in China
}

\author{
Li Mao ${ }^{1,2}$, Xia Liu ${ }^{1,2}$, Wenliang Li ${ }^{1,2}$, Leilei Yang ${ }^{1,2}$, Wenwen Zhang ${ }^{1,2}$ and Jieyuan Jiang ${ }^{1,2^{*}}$
}

\begin{abstract}
Background: Border disease virus (BDV) causes border disease (BD) affecting mainly sheep and goats worldwide. BDV in goat herds suffering diarrhea was recently reported in China, however, infection in sheep was undetermined. Here, BDV infections of sheep herds in Jiangsu, China were screened; a BDV strain was isolated and identified from the sheep flocks in China. The genomic characteristics and pathogenesis of this new isolate were studied.

Results: In 2012, samples from 160 animals in 5 regions of Jiangsu province of China were screened for the presence of BDV genomic RNA and antibody by RT-PCR and ELISA, respectively. $44.4 \%$ of the sera were detected positively, and one slowly grown sheep was analyzed to be pestivirus RNA positive and antibody-negative. The sheep kept virus positive and antibody negative in the next 6 months of whole fattening period, and was defined as persistent infection (PI). The virus was isolated in MDBK cells without cytopathic effect (CPE) and named as JSLS12-01. Near-full-length genome sequenced was 12,227 nucleotides (nt). Phylogenetic analysis based on 5'-UTR and N ${ }^{\text {pro }}$ fragments showed that the strain belonged to genotype 3, and shared varied homology with the other 3 BDV strains previously isolated from Chinese goats. The genome sequence of JSLS12-01 also had the highest homology with genotype BDV-3 (the strain Gifhorn). Experimental infections of sheep had mild clinical signs as depression and short-period mild fever (5 days). Viremia was detected in 1-7 days post-infection (dpi), and seroconversion began after $14 \mathrm{dpi}$.

Conclusions: This study reported the genomic and pathogenesis characterizations of one sheep BDV strain, which confirmed the occurrence of BDV infection in Chinese sheep. This sheep derived BDV strain was classified as BDV-3, together with the goat derived strains in China. These results might be helpful for further understanding of BDV infection in China and useful for prevention and control of BDV infections in the future.
\end{abstract}

Keywords: BDV, Complete genome sequence, Phylogenetic analysis, Experimental infection

\section{Background}

Pestivirus is a genus within family Flaviviridae, comprises four recognized species, namely border disease virus (BDV) of small ruminants, bovine viral diarrhea viruses 1 and 2 (BVDV-1, BVDV-2) of cattle and classical swine fever virus (CSFV) of pigs, respectively [1]. Recently, new pestivirus species, such as Giraffe virus, Pronghorn virus, Bungowannah virus and HoBi-like virus have been discovered $[2,3]$.

BDV infects small ruminants (sheep and goats) and causes border disease worldwide. Several BDV strains

\footnotetext{
*Correspondence: 1776556843@qq.com

Institute of Veterinary Medicine, Jiangsu Academy of Agricultural Sciences; Key Laboratory of Veterinary Biological Engineering and Technology, Ministry of Agriculture; National Center for Engineering Research of Veterinary Bio-products, Nanjing 210014, China

${ }^{2}$ Jiangsu Co-innovation Center for Prevention and Control of Important Animal Infectious Diseases and Zoonoses, Yangzhou 225009, China
}

have been proved to infect pigs and cattle under experimental or nature conditions $[4,5]$. BD shares some similar characteristics with BVDV infections in cattle and goats, however, with more pronounced emphasis on a wide range of productive diseases, such as abortions, stillbirths or mummified fetuses, barren ewes, malformations and the birth of weak lambs, which leads to a considerable economic effect. The affected lambs show abnormal body conformation and "hairy-shaker" syndrome named due to the hairy fleeces and tremors of the suffered lambs [6]. Small weak lambs can be persistently infected (PI) and the virus is wide spread in all organs in infected animals. However, BDV infections in pregnant goats result exclusively in abortions and malformations in fetuses and neonates, and PI goats are rarely found out via placenta [7]. An experiment infection was carried out in pregnant ewes with BDV-4, 
besides a high number of stillbirths up to $32 \%$, significantly reduced bodyweight of lambs was also observed [8]. Although severe clinical outbreaks of BD are unusual, several epizootics have been reported in sheep and goats [9-11].

The pestivirus genome consists of a positive singlestranded RNA approximately $12.3 \mathrm{~kb}$ in length, encoding a single open reading frame (ORF) flanked by 5 '- and 3 'untranslated regions (UTR). The genome codes 4 structural proteins, the capsid $(\mathrm{C})$ and three envelope proteins $\left(E^{\text {rns }}, \mathrm{E} 1\right.$ and $\left.E 2\right)$, plus seven or eight non-structural proteins $[12,13]$. Except the 5 -UTR region, the $\mathrm{N}^{\text {pro }}$ and E2 genes have also been used for genetic classification of new virus isolates $[14,15]$. Based on recent reports, BDV isolates have been divided into seven genotypes at least, and widely distributed in different countries, such as many European countries, Australia, New Zealand, Canada, the United States, India, Turkey, and Japan [7,16]. In 2012, BDV infections were first confirmed in several goat herds suffering serious diarrhea, and three BDV strains were isolated in China [11]. This was the first confirmed evidence of BDV genotype 3 circulations in Chinese goats, In order to further investigate the epidemic information of BDV in goats and sheep in the same regions of China, BDV seroepidemiological survey was carried out in our lab. One BDV strain named JSLS12-01 was isolated from one slowgrown sheep. And the genomic characteristics and pathogenesis of the isolate was determined. The data might be more supplement for BDV epidemiology, pathogenicity as well as its relationship with clinical diseases in China.

\section{Results}

\section{Antibody and viral detection}

One hundred and sixty sera from sheep and goats in five regions of Jiangsu, China were collected and detected by BDV ELISA kits (SVANOVA). The positive rate was $44.4 \%$ (71/160), with $46.3 \%(63 / 136)$ of goats and $33.3 \%$ $(8 / 24)$ of sheep, respectively. The positive rates varied from $16.7 \%(2 / 12)$ to $85.7 \%(12 / 14)$ with the flocks (Table 1). Sero-prevalence was at least $50 \%$ in two sheep herds and one goat herd from two regions of Jiangsu (Table 1).

In the sheep herds, an antibody-negative sheep (2 month old) from Nanjing, Jiangsu was detected positive by RT-PCR, which showed the very bright bands of 290 bp and 225 bp amplified by panpesti generic primers and BDV specific primers PBD1/PBD2, respectively. The RT-PCR products were purified and sequenced, which shared high homology with BDV strains by BLAST analysis. The RT-PCR results also showed two samples from goats were tested positive, 5'-UTR sequences were compared to sequences from GenBank, and shared 100\% homology with JS12-04 strain reported previously.
Table 1 Results of the diagnostic tests performed with samples using ELISA and RT-PCR

\begin{tabular}{lllll}
\hline Farm & Regions & Goats/sheep & ELISA & RT-PCR \\
\hline 1 & Suining, Xuzhou & Goats & $85.7 \%(12 / 14)$ & $1 / 14$ \\
2 & Suining, Xuzhou & sheep & $16.7 \%(2 / 12)$ & $0 / 12$ \\
3 & Siyang, Suqian & Goats & $36 \%(9 / 25)$ & $1 / 25$ \\
4 & Rudong, Nantong & Goats & $34.2 \%(13 / 38)$ & NT \\
5 & Rudong, Nantong & sheep & $50 \%(4 / 8)$ & $0 / 8$ \\
6 & Haian, Nantong & Goats & $49.2 \%(29 / 59)$ & NT \\
7 & Lishui, Nanjing & sheep & $50 \%(2 / 4)$ & $1 / 4$ \\
\hline
\end{tabular}

NT, Sample not tested.

\section{Virus isolation}

The BDV RNA-positive serum was cultured and passaged in MDBK cells. After the third passage, BDV cultures have been positively detected by RT-PCR and confirmed with sequencing. However, no CPE was observed during the process of passage. The new BDV isolate was named as JSLS12-01.

\section{Subsequent clinical observations and serological analysis} Four sampling sheep including the BDV positive were continued to rear for clinical investigation subsequently, with the same feed and management conditions. Compared to the BDV negative sheep, the infected lamb was thinner, weaker, and poorer growth, and the body weight was about $20 \%$ less at the end of fattening period (6 month long). However, no other clinical signs were observed. The four sheep were tested once 4 weeks apart, and BDV RNA was positively detected by RT-PCR and the BDV specific antibody was negative for the original BDV positive animal in the whole grown period.

\section{Complete genome sequencing and phylogenetic analysis} RT-PCR products (Figure 1) were purified and cloned to pJET1.2 vectors for sequencing. The near full genome sequence of BDV JSLS12-01 strain was obtained and deposited in GenBank under accession number KC963426 and reported recently [17], the obtained genome of JSLS12-01 was 12, 227 nucleotides (nt) in length. The isolate shared $80.3 \%$ nucleotide homology and $89.9 \%$ amino acid homology with goat derived strain Gifhorn (a prototype of BDV-3), respectively (Table 2). It shared 72.2-77.6\% homology with other BDV genotypes strains available in GenBank (Table 2). The homology with CSFV and BVDV strains were about $71 \%$ and $67 \%$, respectively (Table 2). The whole genome sequence based phylogenetic analysis indicated that JSLS12-01 was classified into the same branch with Gifhorn with 100\% bootstrap value, and matched up with the result of the Blast analysis. The isolate clearly differed from other BDV strains and other pestivirus species (CSFVs or BVDVs) (Figure 2). 


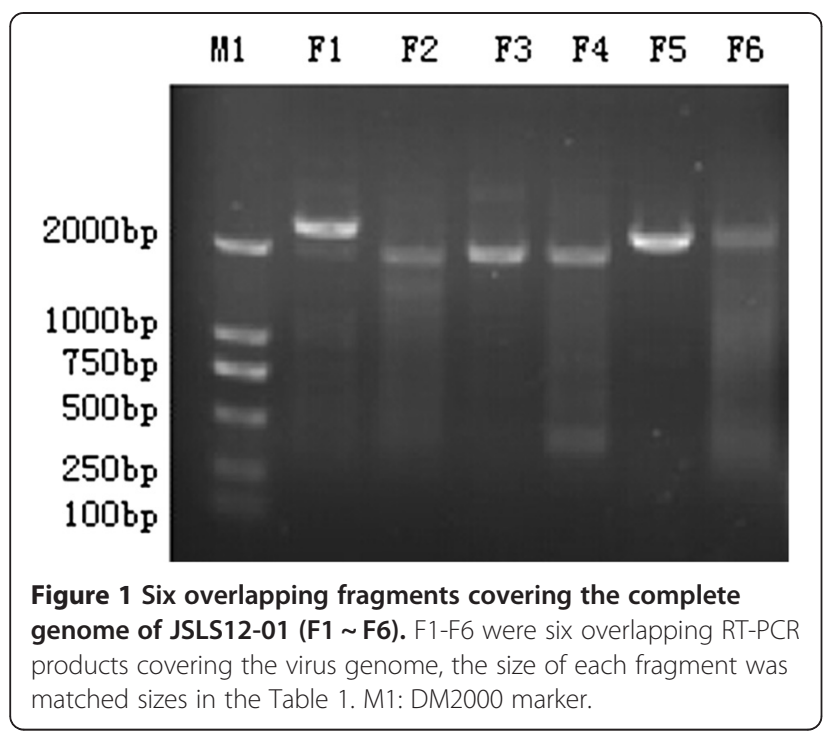

5'-UTR and $\mathrm{N}^{\text {pro }}$ sequences of the virus were aligned with the corresponding sequences of BDV reference strains and the evolutionary relationship between these isolates was estimated by phylogenetic analysis to further characterize the JSLS12-01 isolate. The phylogenetic tree based on 5'-UTR region (225 bp) showed that the JSLS12-01 strain was grouped with BDV-3 respective strains (Figure 3). Comparison of 5'-UTR sequences revealed that BDV JSLS12-01 shared nucleotide identities of $78.6 \%, 83.5 \%$ and $94.4 \%$ with BDV-3 Chinese strains AH12-02, AH12-01 and JS12-04, respectively. The virus was $87.7 \%, 87.4 \%$ and $89.0 \%$ homology with other BDV3 strains including Gifhorn from Spanish goats, 90-F6338 and 90-F-6227 from sheep of France, respectively
(Table 3); and also $82.5 \%$ to $85.7 \%$ with BDV-1; $84.1 \%$ with BDV-2; $76.4 \%$ to $85.1 \%$ with BDV-4; $84.2 \%$ to $85.0 \%$ with BDV-5; 86.7\% with BDV- 6; 71.5\% to $72.9 \%$ with BDV-7; and $70.5 \%$ to $72.6 \%$ with BDV Tunisian; respectively (Table 3 ). The highest identity of nucleotide sequence was $94.4 \%$ with the strain JS12-04 isolated in 2012 from Chinese goats (Table 3). JSLS12-01 shared the highest homology (73.2\% to $80.7 \%)$ with other BDV3 members on the $\mathrm{N}^{\text {pro }}$ sequences (Table 3). And based on the phylogenetic tree of the $\mathrm{N}^{\text {pro }}$ sequences also grouped the strain JSLS12-01 into BDV-3 (data not shown).

\section{Pathogenicity of BDV JSLS12-01}

All 3 lambs (45 day old) infected with BDV JSLS12-01 cell cultures showed only moderated depression without other clinical signs. The infected animals developed high rectal temperatures $\left(40.0-41.0^{\circ} \mathrm{C}\right)$, with peak temperatures appearing on 3-7 day-post-infection (dpi) and returned to the normal level on $8 \mathrm{dpi}$, while the control sheep kept normal during the same period (Figure 4). RT-PCR and virus isolation revealed that the virus could lead to viremia in the infected animals at $1-7 \mathrm{dpi}$. The infected animals began seroconverted on $14 \mathrm{dpi}$ and kept to increase in the following period (Figure 5).

\section{Discussion}

Goats are major rearing small ruminants, and the numbers of sheep and rearing sheep farms are relative a few in Jiangsu and Anhui provinces of eastern China. BDV had been identified in Chinese diseased goats [11]. In the present study, BDV sero-epidemiological survey was carried out for goat and sheep by BDV ELISA kit and

Table 2 The homology of complete coding gene and protein sequence between JSLS12-01 and partial BDV strains

\begin{tabular}{lllll}
\hline $\begin{array}{l}\text { Virus } \\
\text { strain }\end{array}$ & $\begin{array}{l}\text { GenBank } \\
\text { accession number }\end{array}$ & Pestivirus species & JSLS12-01 & Homology of protein (\%) \\
\cline { 5 - 6 } & AB897785 & BDV-1 & 77.5 & 86.4 \\
BD31 & U70263 & BDV-1 & 77.0 & 85.6 \\
X818 & AF037405 & BDV-1 & 76.9 & 85.5 \\
Reindeer-1 & AF144618 & BDV-2 & 77.3 & 86.5 \\
Gifhorn & KF925348 & BDV-3 & 80.3 & 89.9 \\
H2121 & GU270877 & BDV-4 & 77.5 & 87.2 \\
Aveyron & KF918753 & BDV-5 & 77.6 & 87.0 \\
Aydin/04-TR & JX428945 & BDV-7 & 72.2 & 80.1 \\
HCLV & AF091507 & CSFV & 71.0 & 78.5 \\
Shimen & AF092448 & CSFV & 71.2 & 79.0 \\
KE9 & EF101530 & BVDV-1 & 67.0 & 72.0 \\
6151 & JN380083 & BVDV-1 & 67.2 & 72.6 \\
RNV17 & JN380090 & BVDV-2 & 67.4 & 72.3 \\
XJ-04 & FJ527854 & BVDV-2 & 66.9 & 71.7 \\
\hline
\end{tabular}




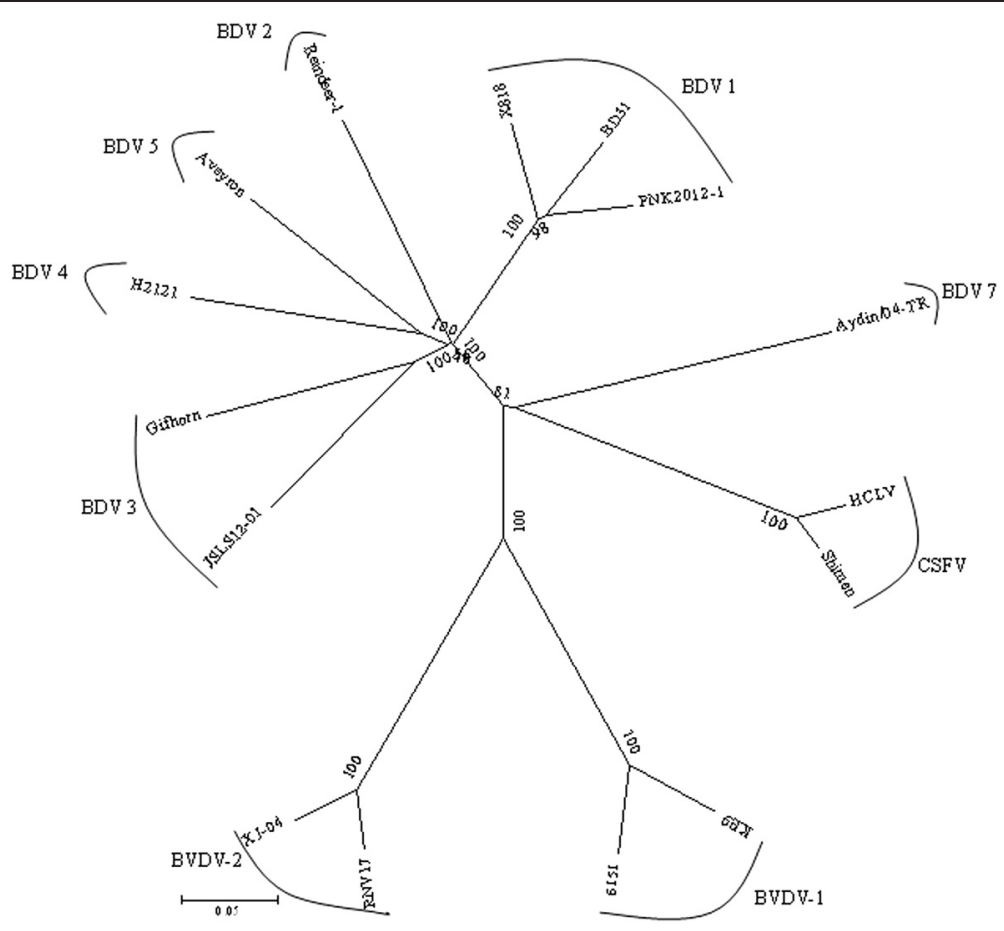

Figure 2 Phylogenetic analysis based on the complete coding sequence of BDV strains using the Neighbour-joining method. The numbers close to the major nodes indicate the bootstrap values (in \%; 1000 replicates). Bar: number of substitutions per site.

RT-PCR. Serum samples from seven flocks (4 of goats and 3 of sheep) in five regions were tested positive by ELISA (Table 1), which indicated the ubiquity of BDV infection in the small ruminant flocks. Four sheep including one was BDV RNA positive with RT-PCR were kept for the next 6 month rearing. The sheep was BDV $\mathrm{Ab}$ negative and viremia for the observation period; and identified as one PI animal according to the reports [7]. The PI sheep mainly showed poor-growing were agreement with BDV-4 virus infections [8]; however, classical clinical signs of BD such as paralysis and an abnormal fleece known as 'hairy shaker' were not appeared. In addition, the previous goat derived BDVs were identified from herds with diarrhea [11]. These uncharacteristic signs emphasized the difficulty of BD diagnosis based on clinical signs and the requirement for routine and accurate laboratory tests.

Phylogenetic segregations of pestiviruses into individual species and subgroups are only identified by the branching order of the phylogenetic tree [18]. The genetic diversity of BDV is greater than that of other pestivirus species. According to the molecular diversity, BDV have been divided to seven groups at least $[7,19,20]$. The near full sequence of the JSLS12-01 had a closer relationship with BDV-3 strains at gene level comparing with other pestivirus reference strains (BDV-1,BDV-2, BDV-3, BDV-4,BDV-5 and BDV-7). And the strain should be one new BDV-3 strain with a lot of nucleotide or amino acid variation to the respective BDV strains (Figure 2, Table 2). The isolate JSLS12-01 was the highest homology with the strain JS12-04 on the 5'-UTR and $\mathrm{N}^{\text {pro }}$ gene compositions, and the two viruses were isolated from sheep or goats in different regions of Jiangsu province, however, the virus JSLS12-01 had much lesser identity with the other two viruses AH12-01 and AH1202 on the gene levels (Table 3 and Figure 3), and the late two were from Anhui province (neighborhood each other). It indicated the epidemic BDV strains in China might have complex endemic situations, and have existed for a relative long period. The BDVs in China have mutated a lot, and may form different subbranches, such as the two strains JS12-04 and JSLS12-01 isolated in Jiangsu province formed one cluster, and the strains AH12-01 and AH12-02 from Anhui were much closed each other (Figure 3).

In addition, based on sequence alignment and phylogenetic analysis, the 4 Chinese BDV strains showed the high diversity of on the 5'-UTR compositions (Table 3) even though all of them were in BDV-3 genotype (Figure 3) [11]. The strain JSLS12-01 was only $83.5 \%$ and $78.6 \%$ homology with the strains AH12-01 and AH12-02 on 5'-UTR gene (Table 3), respectively. Furthermore, it was also found that JSLS12-01 had a very high homology of 5'-UTR sequences with other genotype viruses, such as $85.1 \%, 86.7 \%$ and $85 \%$ with the strains BU1CRA22 (BDV-4), 92-F-7119 (BDV-6) and 93-F-7289 


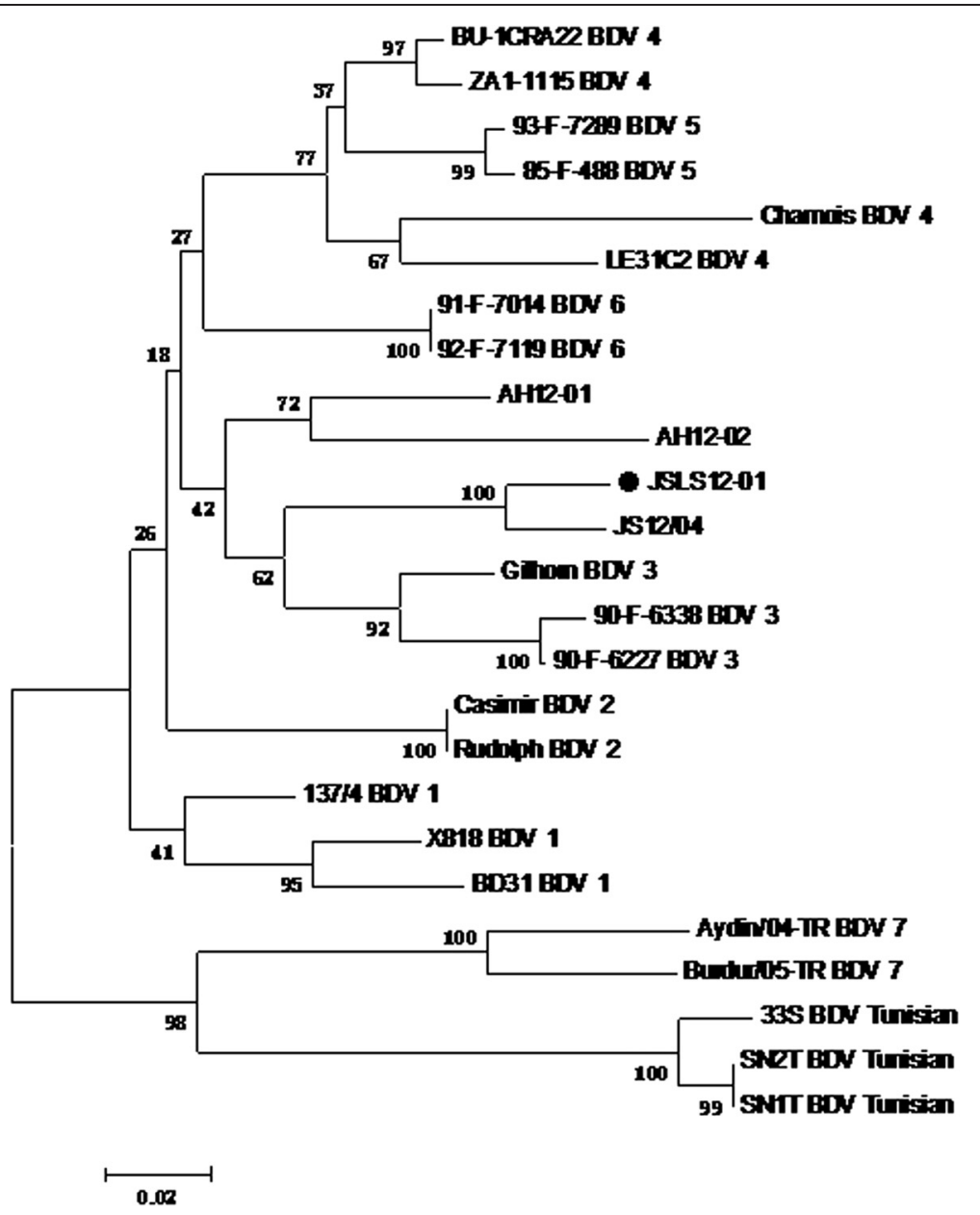

Figure 3 Neighbour-joining phylogenetic tree constructed using 225 nt $5^{\prime}$-UTR fragments of the pestivirus sequences found in this study and from the GenBank. Representatives of BDV sequences have been described in Li et al. [11]. The numbers close to the major nodes indicate the bootstrap values (in \%; 1000 replicates). Bar: number of substitutions per site.

(BDV-5) (Table 3), respectively. It was true that the homology of BDV strains in the same genotype might be much less than the viruses being other genotypes. And it appeared that the BDV genotyping based on the 5'-UTR sequences could be still consummated.

Animal experiment was performed upon conventionally rearing sheep to evaluate the pathogenicity of the new BDV strain. JSLS12-01 could induce mild clinical diseases; the infected animals showed viremia at 1-7 dpi and disappeared after $7 \mathrm{dpi}$, during the same period, mild short-term pyrexia was observed (Figure 4). In addition, the infected animals seroconverted from $14 \mathrm{dpi}$ (Figure 5). No other classical BD symptom was observed. The clinical symptoms of natural infected sheep mainly showed slow-growing and persisted infection. Symptoms of natural and experimental infection were very diverse, this might be related to the immune state and age of the virus infected animals and so on. To date, experimental infections of BDV have not been performed in China, the results would help to understand the pathogenicity of Chinese BDV strains in small ruminants and further systemic studies will be done in the future.

\section{Conclusions}

In conclusion, BDV infections of sheep were demonstrated in China, and the BDV JSLS12-01 strain was clustered in BDV-3 subgroups, the predominant genotype in China. The BDV infections of goats and sheep appeared with various clinical signs and epidemic information. More studies should be carried out to make sure of the virulence and biologic characteristics of BDV.

\section{Methods}

Ethics statement

This study was performed in strict accordance with the guidelines of Jiangsu Province Animal Regulations (Government Decree No 45). The protocol was approved 
Table 3 The homology of $5^{\prime}$-UTR and $\mathbf{N}^{\text {pro }}$ genes between JSLS12-01 and partial BDV strains

\begin{tabular}{|c|c|c|c|}
\hline \multirow[t]{2}{*}{ Virus strain } & \multirow[t]{2}{*}{ Genotype } & \multicolumn{2}{|l|}{ JSLS12-01 } \\
\hline & & $\begin{array}{l}\text { Homology of } \\
5^{\prime} \text {-UTR gene (\%) }\end{array}$ & $\begin{array}{l}\text { Homology of } \\
\mathrm{N}^{\text {pro }} \text { gene (\%) }\end{array}$ \\
\hline $\mathrm{X} 818$ & BDV-1 & 82.5 & 64.1 \\
\hline BD31 & BDV-1 & 82.6 & 63.7 \\
\hline $137 / 4$ & BDV-1 & 85.7 & 66.3 \\
\hline Casimir & BDV-2 & 84.1 & - \\
\hline Rudolph & BDV-2 & 84.1 & - \\
\hline Gifhorn & BDV 3 & 87.7 & 73.2 \\
\hline $\mathrm{AH} 12-01$ & BDV-3 & 83.5 & 75.8 \\
\hline $\mathrm{AH} 12-02$ & BDV-3 & 78.6 & 73.2 \\
\hline$J S 12-04$ & BDV-3 & 94.4 & 80.7 \\
\hline $90-F-6338$ & BDV-3 & 87.4 & 75.0 \\
\hline $90-F-6227$ & BDV-3 & 89.0 & 74.6 \\
\hline BU-1CRA22 & BDV-4 & 85.1 & 64.4 \\
\hline ZA1-1115 & BDV-4 & 83.2 & - \\
\hline Chamois & BDV-4 & 76.4 & - \\
\hline LE31C2 & BDV-4 & 79.3 & - \\
\hline $85-F-488$ & BDV-5 & 84.2 & 70.1 \\
\hline 93-F-7289 & BDV-5 & 85.0 & 70.5 \\
\hline 91-F-7014 & BDV-6 & 86.7 & 68.1 \\
\hline $92-F-7119$ & BDV-6 & 86.7 & 68.5 \\
\hline Burdur/05-TR & BDV-7 & 72.9 & 54.7 \\
\hline Aydin/04-TR & BDV-7 & 71.5 & 55.7 \\
\hline SN1T & BDV Tunisian & 72.6 & 53.7 \\
\hline 335 & BDV Tunisian & 70.5 & 53.7 \\
\hline SN2T & BDV Tunisian & 71.3 & 53.9 \\
\hline
\end{tabular}

$-:$ The sequence could not be obtained in GenBank.

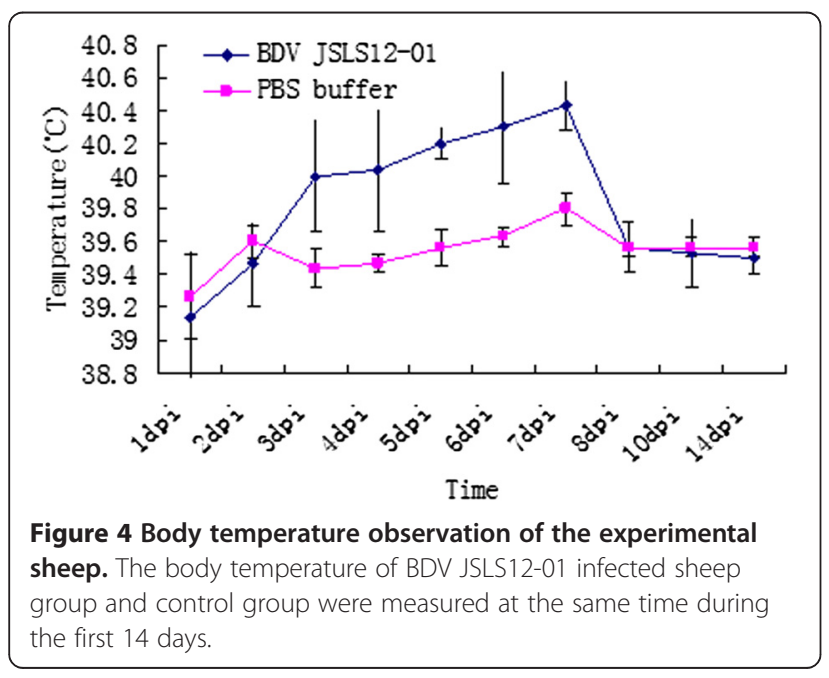

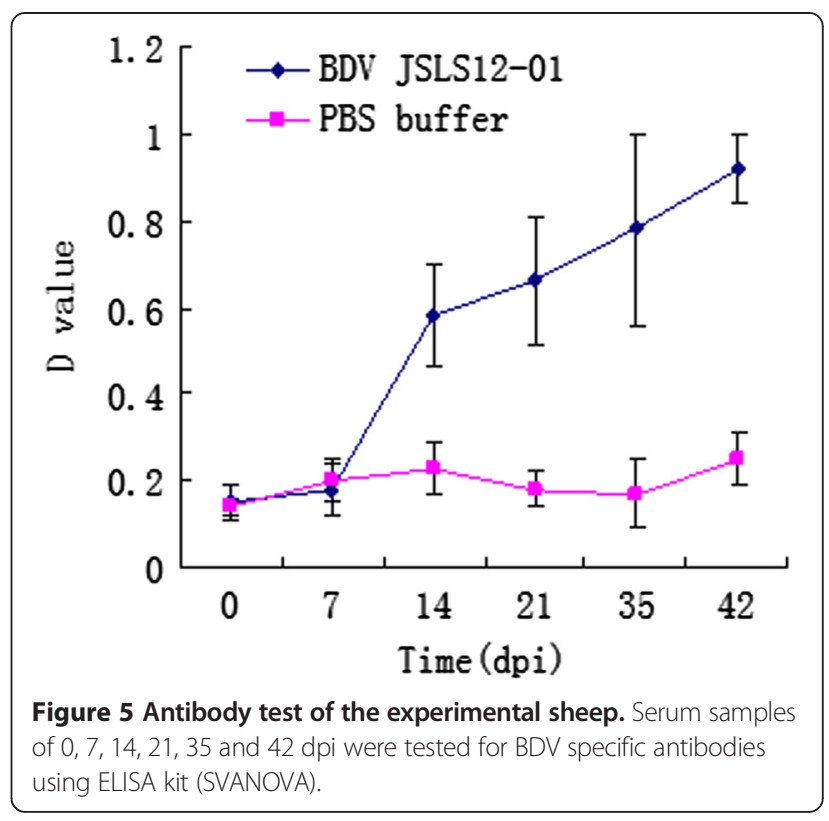

by the Committee on the Ethics of Animal Experiments of the Institute of Veterinary Medicine, Jiangsu Academy of Agricultural Sciences (JAAS No 20100604).

\section{Clinical sampling and observation}

Serum samples were collected from 3 young sheep farms and 4 goat farms (about 2 months old) from 5 different regions in Jiangsu province of China (Table 1). A total of 24 sera from sheep and 136 sera from goats were collected. The sheep tested for BDV positive were continuously carried out for subsequent clinical observations and serological analysis in next 6 months (the fattening period) after the first sampling.

\section{ELISA}

BDV antibody detection was performed on serum samples of goats and sheep using a commercially available kit (SVANOVA BDV-Ab kit, SVANOVA Biotech, Uppsala, Sweden) according to the manufacturer's instructions.

\section{Virus isolation}

Virus isolation was carried out on the positive samples of pestivirus 5'-UTR RT-PCR as reports [16] and briefly introduced as following: the serum samples were centrifuged at $12,000 \mathrm{rpm}$ for $20 \mathrm{~min}$ at $4^{\circ} \mathrm{C}$ and filtered through $0.22 \mu \mathrm{m}$ filter, and subsequently inoculated onto confluent monolayers of Madin-Darby bovine kidney (MDBK) cells (obtained from China Institute of Veterinary Drugs Control) to culture for 96 hours with $1 \%$ FCS DMEM at $37^{\circ} \mathrm{C}$ and $5 \% \mathrm{CO}_{2}$ conditions. The original cells and FCS were proven to be free of pestivirus antigen and antibodies. The isolation of BDV was 
checked by RT-PCR as next described using Panpesti generic primers and BDV specific primers $\mathrm{PBD} 1 / \mathrm{PBD} 2$ $[21,22]$.

\section{RT-PCR detection and complete genomic sequence analysis}

Sera from sheep and goats were tested for the presence of pestivirus by RT-PCR method. To detect the BDV virus, total RNA was extracted from serum samples and cell cultures by using the TRizol reagent (Invitrogen) according to the manufacturer's instruction. RT-PCR was carried out in a $50 \mu \mathrm{L}$ reaction mixture containing $1 \times$ RT-PCR buffer (TAKARA, Bio, Inc.), 20 pM of each primer (Panpesti generic primers and BDV specific primers PBD1/PBD2 targeting 5'-UTR, with expected product sizes of $290 \mathrm{bp}$ and $225 \mathrm{bp}$, respectively) [21,22], $2 \mathrm{U}$ of one-step Enzyme Mix (TAKARA, Bio, Inc.) and $4 \mu \mathrm{L}$ of RNA. The reaction was run in a thermocycler (Mjmini, BIO-RAD) according to the following program: reverse transcription at $50^{\circ} \mathrm{C}$ for $30 \mathrm{~min}$, denaturation at $95^{\circ} \mathrm{C}$ for $5 \mathrm{~min}, 35$ cycles at $94^{\circ} \mathrm{C}$ for $30 \mathrm{~s}, 54^{\circ} \mathrm{C}$ for $30 \mathrm{~s}$ and $72^{\circ} \mathrm{C}$ for $45 \mathrm{~s}$, terminated with a final extension of $10 \mathrm{~min}$ at $72^{\circ} \mathrm{C}$.

For the genomic long RNA RT-PCR, the extension time was $1 \mathrm{~kb}$ for $1 \mathrm{~min}$. Amplification products were detected by electrophoresis in $1.2 \%$ agarose gels. Positive RT-PCR fragments were purified (Axygen), cloned to pJET1.2 vector (Thermo), and then transformed to $E$. coli DH5 $\alpha$. Positive clones, as confirmed by PCR and enzyme digestion, were sequenced. Three positive clones of each RT-PCR fragment were sequenced using the appropriate PCR primers for correct check.

Briefly, six pairs of primers were designed to amplify the 6 overlapping fragments covering the virus genome, and summarized as Table 4 . The retrieved sequences were edited and assembled with SeqManTM program version 5.03 of the DNASTAR package to obtain the complete sequence of this new BDV strain.

\section{Phylogenetic analysis}

The complete coding sequence of the virus was aligned with some represented BDV, BVDV 1, BVDV 2 and CSFV strain genome sequences. The 5'-UTR and $\mathrm{N}^{\text {pro }}$ sequences were analyzed with sequences of BDV reference strains using 1.83 and MEGA 4.0.2, the 225 bp 5'UTR fragments (PBD1/PBD2 product) and $487 \mathrm{bp} \mathrm{N} \mathrm{N}^{\text {pro }}$ gene (corresponding to 394-880 bp of Gifhorn genome) sequences were used for analysis, respectively. Phylogenetic analysis was carried out using the neighbor-joining (NJ) method using 1000 replicates for determination the bootstrap values.

\section{Experimental infection}

Six one-month-old healthy sheep were tested negative for pestivirus (BDV and BVDV) infections by commercial ELISA kit (BDV: SVANOVA and BVDV: BIO-X) and RTPCR mentioned above. They were further confirmed to be free of micoplasma infections by PCR. The sheep were randomly divided into two groups, with 3 animals in each group. Sheep of the experimental group was infected by intramuscular injection with $10^{5}$ TCID $_{50}$ of BDV JSLS1201 cell cultures, while the sheep in control group were inoculated with PBS buffer. All animals were monitored daily for clinical signs including depression, nasal discharge, diarrhea, coughing and rectal temperature. Serum samples were collected at day -2 to 0 prior to infection and $1,3,5,7,14,21,28,35$ and 42 dpi. Serum samples of days $1,3,5,7,14$ and 21 were tested for viremia by RTPCR described above. And the procedures to isolate BDV from the sera were described above. Serum samples of days $0,7,14,21,35$ and 42 were tested for BDV specific antibodies using commercial ELISA kit (SVANOVA).

Table 4 The primer sequence of the complete genome sequence

\begin{tabular}{|c|c|c|c|c|}
\hline Amplified fragments & primer & Primer sequences $\left(5^{\prime}->3^{\prime}\right)$ & Location (bp) & Fragment size \\
\hline \multirow[t]{2}{*}{ F1 } & BVDV-F & GCCATGCCCTTAGTAGGACTAGC & $1 \sim 23$ & $2200 \mathrm{bp}$ \\
\hline & BDV-2300R & TATCAGGAAGGCTGTTGTCGA & $2255 \sim 2273$ & \\
\hline \multirow[t]{2}{*}{ F2 } & BDV-2240 F & TTGGTGGCCATACGAGACAAC & $2144 \sim 2164$ & $1900 \mathrm{bp}$ \\
\hline & BDV-4140R & TGTCAAGATGAAGAATAGGGG & $4023 \sim 4043$ & \\
\hline \multirow[t]{2}{*}{ F3 } & BDV-4010 F & AAGCAGTGGCTACAATCCGTG & $3912 \sim 3932$ & $1950 \mathrm{bp}$ \\
\hline & BDV-5960R & СATCTCTCCAATCCTCAGGTT & $5865 \sim 5885$ & \\
\hline \multirow[t]{2}{*}{ F4 } & BDV-5940 F & GCAGAAGCACCCTAGCATAGC & $5840 \sim 5860$ & $2000 \mathrm{bp}$ \\
\hline & BDV-7940R & TATGACTACGCTCTCCAGCCG & $7929 \sim 7945$ & \\
\hline \multirow[t]{2}{*}{ F5 } & BDV-7885 F & GCCTTACGCATCTCAAGCCCTC & $7787 \sim 7808$ & $2200 \mathrm{bp}$ \\
\hline & BDV-10110R & TGCCTCGTATGGGTGTATITTC & $10001 \sim 10022$ & \\
\hline \multirow[t]{2}{*}{ F6 } & BDV-10010 F & CAGAGCATATGGTGTCAGCATATCAG & $9907 \sim 9932$ & $2300 \mathrm{bp}$ \\
\hline & BDV-12326R & GGGGCTGTTAGGGTTITTCCTTAATCC & $12201 \sim 12227$ & \\
\hline
\end{tabular}




\section{Competing interests}

The authors declare that they have no competing interests.

\section{Authors' contributions}

$L M, X L, W L$, and JJ participated in the design and conducted the majority of the experiments in the study. LM drafted the manuscript. LY and WZ contributed to the samples detection. JJ revised the manuscript. All authors read and approved the final manuscript.

\section{Acknowledgements}

This work was supported by the Special Fund for Independent Innovation of Agricultural Science and Technology in Jiangsu province [CX (14)2090] and Jiangsu Provincial Natural Science Foundation of China [BK20130729].

Received: 9 June 2014 Accepted: 27 November 2014

Published online: 08 February 2015

\section{References}

1. Vilcek S, Leskova V, Meyer D, Postel A, Becher P: Molecular characterization of border disease virus strain Aveyron. Vet Microbiol 2014, 171:87-92.

2. Liu L, Xia H, Wahlberg N, Belák S, Baule C: Phylogeny, classification and evolutionary insights into pestiviruses. Virology 2009, 385:351-357.

3. Mao L, Li W, Zhang W, Yang L, Jiang J: Genome sequence of a novel Hobi-like pestivirus in China. J Virol 2012, 86:12444.

4. Cabezón O, Rosell R, Sibila M, Lavín S, Marco I, Segalés J: Experimental infection of pigs with Border disease virus isolated from Pyrenean chamois (Rupicapra pyrenaica). J Vet Diagn Investig 2010, 22:360-365.

5. Sharp MW, Rawson BC: The cost of border disease infection in a commercial flock. Vet Rec 1986, 119:128-130.

6. Nettleton PF, Gilray JA, Russo P, Dlissi E: Border disease of sheep and goats. Vet Res 1998, 29:327-340.

7. Oguzoglu TC, Tan MT, Toplu N, Demir AB, Bilge-Dagalp S, Karaoglu T, Ozkul A, Alkan F, Burgu I, Haas L, Greiser-Wilke I: Border disease virus (BDV) infections of small ruminants in Turkey: A new BDV subgroup? Vet Microbiol 2009, 135:374-379.

8. García-Pérez AL, Minguijón E, Estévez L, Barandika JF, Aduriz G, Juste RA, Hurtado A: Clinical and laboratorial findings in pregnant ewes and their progeny infected with Border disease virus (BDV-4 genotype). Res Vet Sci 2009, 86:345-352.

9. Mainar-Jaime RC, Vazquez-Boland JA: Associations of veterinary services and farmer characteristics with the prevalences of brucellosis and border disease in small ruminants in Spain. Prev Vet Med 1999, 40:193-205.

10. Valdazo-González B, Alvarez-Martinez M, Greiser-Wilke I: Genetic typing and prevalence of Border disease virus (BDV) in small ruminant flocks in Spain. Vet Microbiol 2006, 117:141-153.

11. Li W, Mao L, Zhao Y, Sun Y, He K, Jiang J: Detection of border disease virus (BDV) in goat herds suffering diarrhea in eastern China. Virol J 2013, 10:80. doi:10.1186/1743-422X-10-80.

12. Becher $P$, Orlich $M$, Thiel $\mathrm{HJ}$ : Complete genomic sequence of border disease virus, a pestivirus from sheep. J Virol 1998, 72:5165-5173.

13. Collett MS, Larson R, Gold C, Strick D, Anderson DK, Purchio AF: Molecular cloning and nucleotide sequence of the pestivirus bovine viral diarrhea virus. Virology 1988, 165:191-199.

14. Couvreur B, Letellier C, Collard A, Quenon P, Dehan P, Hamers C, Pastoret PP, Kerkhofs P: Genetic and antigenic variability in bovine viral diarrhea virus (BVDV) isolates from Belgium. Virus Res 2002, 85:17-28.

15. Hurtado A, García-Pérez AL, Aduriz G, Juste RA: Genetic diversity of ruminant pestiviruses from Spain. Virus Res 2003, 92:67-73.

16. Strong R, La Rocca SA, Ibata G, Sandvik T: Antigenic and genetic characterisation of border disease viruses isolated from UK cattle. Vet Microbiol 2010, 141:208-215.

17. Liu X, Mao L, Li W, Yang L, Zhang W, Wei J, Jiang J: Genome Sequence of a Border Disease Virus in China. Genome Annouc 2013, 1(6).

18. Becher P, Avalos Ramirez R, Orlich M, Cedillo Rosales S, König M, Schweizer M, Stalder H, Schirrmeier H, Thiel HJ: Genetic and antigenic characterization of novel pestivirus genotypes: implication for classification. Virology 2003, 311:96-104.

19. Dubois E, Russo P, Prigent M, Thiéry R: Genetic characterization of ovine pestiviruses isolated in France, between 1985 and 2006. Vet Microbiol 2008, 130:69-79.
20. Thabti F, Letellier C, Hammami S, Pépin M, Ribière $M$, Mesplède A, Kerkhofs $P$, Russo P: Detection of a novel border disease virus subgroup in Tunisian sheep. Arch Virol 2005, 150:215-229.

21. Albayrak H, Gumusova SO, Ozan E, Yazici Z: Molecular detection of pestiviruses in aborted foetuses from provinces in northern Turkey. Trop Anim Health Prod 2012, 44:677-680.

22. Vilcek $S$, Herring AJ, Herring JA, Nettleton PF, Lowings JP, Paton DJ: Pestiviruses isolated from pigs, cattle and sheep can be allocated into at least three genogroups using polymerase chain reaction and restriction endonuclease analysis. Arch Virol 1994, 136:309-323.

\section{Submit your next manuscript to BioMed Central and take full advantage of:}

- Convenient online submission

- Thorough peer review

- No space constraints or color figure charges

- Immediate publication on acceptance

- Inclusion in PubMed, CAS, Scopus and Google Scholar

- Research which is freely available for redistribution

Submit your manuscript at www.biomedcentral.com/submit
C Biomed Central 